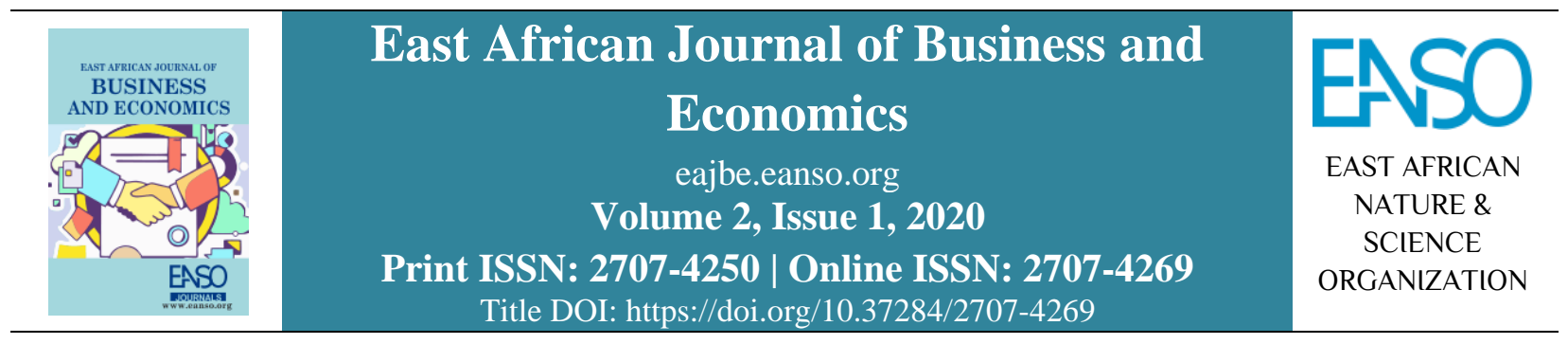

Original Article

\title{
Air Transport and Its Impact on the Tourism Industry in Rwanda: Case of RwandAir
}

\author{
Ronald Kalulu ${ }^{* 1}$, Dr. Emmy Tushabe ${ }^{1}$ \& Abel Chondo ${ }^{1}$ \\ ${ }^{1}$ Department of Tourism and Hospitality, the University of Tourism, Technology and Business Studies, Rwanda. \\ *Correspondence email: kaluluronald@gmail.com.
}

Article DOI: https://doi.org/10.37284/eajbe.2.1.185

\section{Date Published: ABSTRACT}

24 July 2020 The study focused on the air transportation and its impact on the tourism industry in Rwanda; the case of RwandAir. The study objectives were to

Keywords: identify the contributions of air transportation to the development of tourism industry in Rwanda; to establish the challenges facing the air transport sector

RwandAir, and to propose strategic measures to mitigate the challenges. The study used a

Tourism,

Air Transport, cross-sectional survey thus both the qualitative and quantitative approaches

Development. were applied. The study used closed-ended questionnaires, structured interview, as well as document review. Purposive sampling was used on the key managers of both RwandAir and Rwanda Development Board. The study targeted 700 international tourists and 200 domestic tourists (conveniently selected), as well as structured interview with 30 senior officers of RwandAir and 20 senior officers of RDB, hence making the total population to be 950 respondents. The study sample size was 274 respondents. However, after validating the returned questionnaires, only 240 questionnaires were found to be valid. It was revealed that RwandAir greatly contributes to tourism development in many ways such as marketing, job creation, transporting tourists, providing a convenient, quick and safe way to get into the country among others. It was revealed by the world bank that international tourism arrivals in 2016 was 932000 tourists bringing in $25.85 \%$ of total exports and total imports and expenditure on travel service es was $11.99 \%$ in Rwanda. The number of tourists' arrivals was limited to arrivals by air. However, RwandAir and air transport in general faces changing oil prices, expensive jets, terrorism in neighbouring countries, limited funding, skills gap in aviation sector (lack of technical engineers and pilots), geographical location, inadequate infrastructure and to a great extent, lack of safety compliance. The strategies that can be adopted to improve air transport sector are: more funding to air transport industry by government; oil and energy negotiations with oilproducing countries; skills enhancement like training local pilots and engineers; improved airport infrastructure in Rwanda e.g. at Kigali 
international airport and other domestic airports; space agreements as well as benchmarking best airline companies like Qatar and emirates and others in the region. The study recommends tax concessions for the air transport, oil negotiations, opening up and re-development of the domestic airports in the country, reduced prices for incoming tourists using RwandAir, partnerships between government and private sector in developing air transport, increased training of aviation staff among others. It is believed that when these are done, then air transport will continue to positively transform tourism into a better and developing sector with sustained customer base hence national development.

\section{APA CITATION}

Kalulu, R., Tushabe, E., \& Chondo, A. (2020). Air Transport and Its Impact on the Tourism Industry in Rwanda: Case of RwandAir. East African Journal of Business and Economics, 2(1), 43-52. https://doi.org/10.37284/eajbe.2.1.185

\section{CHICAGO CITATION}

Kalulu, Ronald, Emmy Tushabe, and Abel Chondo. 2020. "Air Transport and Its Impact on the Tourism Industry in Rwanda: Case of RwandAir”. East African Journal of Business and Economics 2 (1), 43-52. https://doi.org/10.37284/eajbe.2.1.185.

\section{HARVARD CITATION}

Kalulu, R., Tushabe, E. and Chondo, A. (2020) "Air Transport and Its Impact on the Tourism Industry in Rwanda: Case of RwandAir”, East African Journal of Business and Economics, 2(1), pp. 43-52. doi: 10.37284/eajbe.2.1.185.

\section{IEEE CITATION}

R. Kalulu, E. Tushabe, and A. Chondo, "Air Transport and Its Impact on the Tourism Industry in Rwanda: Case of RwandAir", EAJBE, vol. 2, no. 1, pp. 43-52, Jul. 2020.

\section{MLA CITATION}

Kalulu, Ronald, Emmy Tushabe, and Abel Chondo. "Air Transport and Its Impact on the Tourism Industry in Rwanda: Case of RwandAir”. East African Journal of Business and Economics, Vol. 2, no. 1, July 2020, pp. 43-52, doi:10.37284/eajbe.2.1.185

\section{INTRODUCTION}

Tourism is the movement of people between places for purposes such as exploring new places, noveltyseeking and getting to know different cultures and people (Leiper, 1979). Thus, transport has been an integral part of the tourism industry as it links tourists with various tourist attractions. There is also a general agreement that tourism expands more when there are better transportation systems. (Hall \& Hall, 2001; Hall, Segal, \& Osborne, 1997). The United Nations World Tourism Organization estimates that tourism contributes approximately 75 million direct jobs worldwide as well as indirect employment opportunities to communities and offers women and youth fast entry into the workforce (UNWTO, 2012). Over the last ten years, tourism in Rwanda has recorded significant growth potential, with the industry's contribution to the country's GDP growing at a steady rate (Meleddu, 2014). The industry's contribution to national output (GDP) has shown a steady increase from $0.5 \%$ in 1995 to $17.2 \%$ in 2010 (Ndahimana, Musonera \& Weber, 2013). Tourism industry today, is the number one foreign exchange earner for Rwanda, just as it is in other economies of the world and thus plays a vital role in the social, economic and environmental development of many countries including Rwanda, the home to a hugely diverse population of fauna and flora as well as the rich history and culture (Nsabimana, 2010; Nsabimana \& Spencer, 2013; Hall \& Hall, 2001; Varhela, 2013).

The country was identified at the World Investment Conference in Geneva (John Menzies PLC, 2015) as one of the countries in East Africa with a significant potential for developing tourism although being landlocked and with limited resources, unlike most African countries. Upon this basis, the government of Rwanda in the way of reducing this gap, identified tourism to provide the 
best alternative for economic development as it can contribute to poverty reduction, create jobs as well as contributing to the national income (Nsabimana \& Spencer, 2013; Varhela, 2013). This is in agreement with Samimi, Sadeghi and Sadeghi (2017). However, the tourism industry can only operate with the availability of other tourism essentials such as transportation, accommodation, entertainment, food and so on (Kalulu \& Tushabe, 2019, Nsabimana, 2010). It is also clear that tourism cannot be developed without a functioning transportation system as more than 74 percent of international tourists travelling to Rwanda use air transport. This shows how vital air transportation is for Rwanda and its tourism industry (Rwunguko, 2015). Therefore, to accommodate the increasing number of tourists while maintaining sustainable mobility at the destination, it is important to encourage a modal shift and improve the efficiency of the transport system. Several actions are required to achieve sustainable mobility including encouraging greater efficiency in the transport system as air transport brings tourists and host nations' cultures together and brings several opportunities in a responsible and strategic way as people today "care about the traveling time more than the traveling distance" (ICAO, 2010; Simpson, 2008).

Air transport is the fastest and the most regulated transportation system currently transporting more than 3.1 billion people and generating about 58.1 million jobs. It has become one of the best and most popular transportation for long-distance travels in the world today. With new technology and development came along the fastest jet planes and aircrafts that allowed traveling faster than ever. Air transport makes it possible to reach some of the world's remote places and helps to grow tourism industry and economy of developing countries like Rwanda (ICAO, 2010). The expansion of air transport has resulted in the uncovering of many untouched and non-popular areas (such as Kinigi sector, the home to the gorilla in the volcanoes national park) to non-Rwandans thus leading to its development when several tourists visited and continue to visit it in addition to other touristic products in the country like Nyungwe national park, Akagera national park, among others (RDB, 2014).

Nowadays, travelers can explore new areas and travel long-distance in the shortest time; especially those who want to arrive at their destinations quickly (Fletcher, Fyall, Gilbert \& Wanhill, 2017). However, despite the benefits that air transport brings to the economy, few studies have been undertaken, especially on the impacts air transport has on tourism development in Rwanda. For instance, the World Bank report of 2012 indicated that 626,925 people were transported into Rwanda via air transport (Shackley, 1995; World Bank, 2012).

RwandAir is the flag carrier of Rwanda operating domestic and international services within East Africa and beyond and currently serves 18 destinations with the slogan "Fly our dream to the heart of Africa” (RURA, 2014). In 2015, RwandAir carried 600,000 passengers including tourists who came to visit Rwanda's natural and cultural aspects, and it was the same year it became IATA member. During the recently held tourism expo in Uganda, RwandAir was awarded the best airline in the region for the year 2016. Therefore, the study explored the contribution of air transport to tourism development in Rwanda using the national career as the case study with the following study objectives: to identify the contribution of air transport to the development of tourism industry in Rwanda; to establish the challenges facing air transport sector in Rwanda and to propose strategic measures to improve air transport in Rwanda.

\section{The Study Context}

Air transport refers to a method of transport by which passengers, mail, and cargo are conveyed by air. The chief advantage of this method is the considerable amount of time saved because of the 
high speed of the flight (Bieger \& Wittmer, 2006; ICAO, 2010). It supports the tourism industry development. RwandAir, the national airline of the Republic of Rwanda, has garnered a lot of attention in the past three years since 2009 (ICAO, 2010). So much that the airline has earned the proud moniker of "the Fastest Growing Airline in Africa" (Kuperman, 2000; Yan-jun, 2010). Since 2009, RwandAir built a reputation of being a time-keeper and offering affordable fare prices to most capital cities in Eastern Africa while operating a young, state-of-the-art fleet. Passenger numbers would double each year as the airline acquired new aircraft and opened new destinations. Today the airline operates a fleet composed of four Boeing $737 \mathrm{NG}$ series, two CRJ-900 NextGen and one Dash-8 and serves all major cities in the Africa with Dubai being the only destination outside the African continent (ICAO, 2010; Rwunguko, 2015).

The air transportation system has been developing and growing with airlines operating from many countries around the globe (African Infrastructure, 2009; SITA, 1995). These kinds of provisions of the air service agreements provide over 5.2 million seats on air transportation to or from Rwanda, about 75 percent of international tourist travel to Rwanda through air transportation. This high number of traveling tourists suggests that the air transportation is one of the most important parts of Rwanda's tourism industry (Bieger \& Wittmer, 2006; Henninger, 2009; IATA, 2009; ICAO, 2010). Today, Rwanda receives more than 1.7 tourists and majority of them come to Rwanda using air transportation. For instance, the international tourist arrivals, majority of the air travellers, were occasioned by a growing number of high-end visitors mostly from the United States of America, Australia, China, France, Belgium, Nigeria, United Kingdom, Germany, Uganda, DRC, and other countries (ICAO, 2010; infrastructure, 2009). In Africa, Nigeria was dominant suppliers of tourists to Rwanda due to the flight link that the national carrier RwandAir has established as the national airline now connects Kigali and two cities of Nigeria - Lagos and Abuja thus Nigeria ranks top African spenders, spending an average of $\$ 1,498$ per stay, ranking higher than Australians and only slightly below the French.

This was further stated by Belize Kariza, the Chief Tourism Officer at RDB when she said that “... an eight per cent growth in the number of international visitors to Rwanda in 2019 grew by 25 per cent in 2018 to $\$ 19.2 \mathrm{M}$ and $\$ 408$ in 2019 even when the permits prices were revised from $\$ 750$ to $\$ 1500$ in 2016...", (RDB, 2020). This money was earned from the sale of 15,132 gorilla permits during the year yet in 2016 prior to the increase of permit price, 22,219 were sold, raking in $\$ 15 \mathrm{~m}$ in revenue. American luxury tourists to Rwanda have grown by 114 per cent year on year, Kariza said, quoting the latest data released by Virtuoso, an American luxury tourism network. (RDB,2020). The other airlines operating in Rwanda include Air Burundi, Brussels Airlines; Coastal Aviation; Ethiopian Airline; Kenya Airways, KLM, Qatar Airways, and the Cargo Airlines (African Infrastructure, 2009).

Air transport has also resulted to an increase in demand for hotel rooms up to 14,000 in 2018 from barely 4,000 in 2009. This is attributed to the entry of new operators who have opened up new facilities such as Singita, Magashi camp and Bisate Lodge by Wilderness Safaris, and Amakoro Songa Kinigi Lodge among others, (Belize Kariza RDB,2020). Figures from RDB, revealed that currently, Akagera National Park was visited by 51, 724 visits in 2018, an increase of 17 per cent compared to 2017 while Nyungwe National Park received 15, 665 visitors, up 9 per cent.

Government of Rwanda has started a policy of providing instant arrival VISA up to a maximum of 30 days at the Airport after the payment. However, the duration can be extended later at the tourist ministry if needed. This kind of service will promote and increase the international tourist arrival and air traffic to Rwanda. Rwanda has an 
incredible environment that makes it have a huge potential for tourism development. However, due to the geographical difficulties, construction of road transportation and railway becomes very difficult and costly. In that situation, air transportation is the only option for means of transportation (Indian, PM. 2011; Henninger, 2009; Sitaula, 2010).

Rwanda's tourism offers artificial, cultural and natural attractions. However, it can only operate efficiently with the availability of other tourism essentials such as transportation, accommodation, entertainment, food, and so on. It is also clear that tourism cannot be developed without a functioning transportation system as more than 75 percent of international tourists travelling to Rwanda choose air transportation (IATA, 2009; ICAO, 2010; SITA, 1995). This shows how vital air transportation is for Rwanda and its tourism industry (Filimonau, Dickinson \& Robbins, 2014; Higham, Cohen \& Cavaliere, 2014; Varley, 2005).

For a developing country like Rwanda, transportation plays a very important role in its development as Rwanda is a landlocked country and therefore needs all types of transportation systems to operate efficiently. A well-developed and managed transportation system is the backbone of countries like Rwanda for their tourism development (RURA, 2014) as well as for the prosperity of Africa as it opens up business opportunities across borders. "Africa has about 16 landlocked countries, including Rwanda, and air transport is a key element in unlocking these countries" (Baldasano, Valera \& Jimenez, 2003; Filimonau, Dickinson \& Robbins, 2014). Air transportation is vital for tourism as more than a half of the total international tourists and around 35 percent of goods in international trade are transported via air transportation due to its being fast, safe and reliable (IATA, 2009; ICAO, 2010). Therefore, to accommodate the increasing number of tourists while maintaining sustainable mobility at the destination, it is important to encourage a modal shift and improve the efficiency of the transport system (Filimonau, Dickinson \& Robbins, 2014; Henninger, 2009; Infrastructure, 2009).

\section{METHODOLOGY}

The study used a cross-sectional survey to establish the contribution of air transport towards tourism development in Rwanda. The study used both the qualitative and quantitative approaches to gather data for the study. The study used closed-ended questionnaires (Iglesias \& Torgerson, 2000), structured interview as well as document review. Purposive sampling was used on the key managers of both RwandAir and RDB. The study targeted 700 international tourists and 200 domestic tourists (conveniently selected), as well as structured interview with 30 senior officers of RwandAir and 20 senior officers of RDB, hence making the total population to be 950 respondents. The study sample size was 274 respondents determined using Krejcie and Morgan (1970) method. However, after validating the returned questionnaires, only 240 questionnaires were found to be valid and data was analyzed using descriptive frequencies (Carmines \& Zeller, 1979).

\section{RESULTS AND DISCUSSION}

The major contributions of air transport towards tourism were: RwandAir carries the country's tourists in the country; markets tourism outside Rwanda while carrying out business; air transport allows travellers to experience different natural, social and cultural aspects of Rwanda with greater value; it opens up business opportunities across borders by bringing employment opportunities in a responsible and strategic way; it provides jobs to a spectrum of people like tourism students, guides, security, pilots, engineers, transport officers, etc; and last but not the least, RwandAir provides a convenient, quick and safe way to get into the country as shown in the graph below; 


\section{Contribution of air transport to tourism sector in Rwanda}

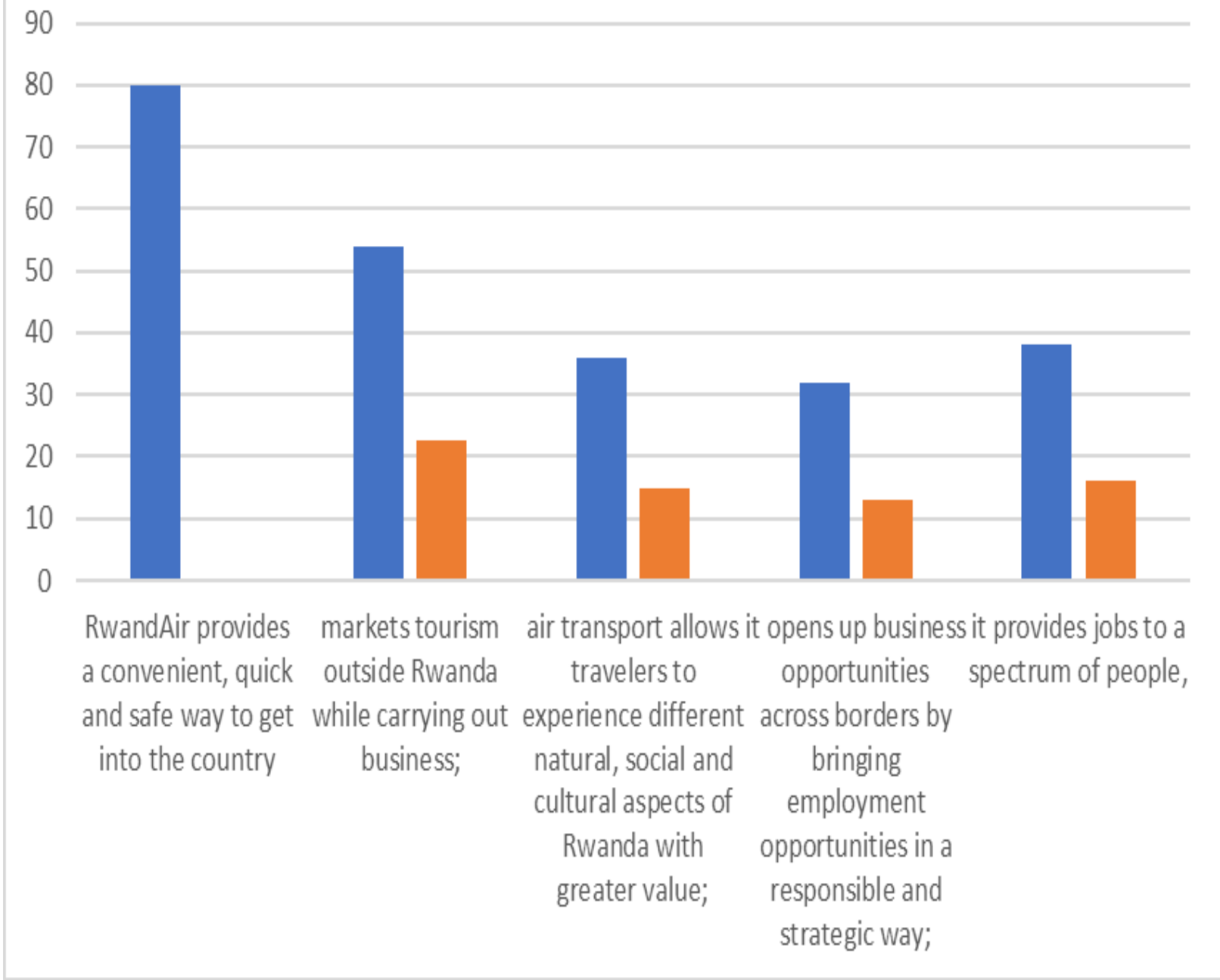

Source: Field survey (2019)

However, RwandAir like any other airline player, face a lot of challenges while carrying out its operations both in and outside Rwanda. Most challenges accrue from within the country, although competition and experience are others affecting operations. Therefore, such challenges were asked from respondents and they pointed out expensive jets, limited funding, skills gap in aviation sector where Rwanda has to import skills, terrorism in neighbouring countries like Kenya and DRC, geographical location factors like being landlocked, changing oil prices, Inadequate infrastructure and to a great extent, lack of safety compliance. The following factors have affected not only RwandAir but the tourism industry in general thus some customers are becoming selective to certain destinations to go while leaving others as revealed by the pie chart below. 
East African Journal of Business and Economics, Volume 2, Issue 1, 2020

Article DOI: https://doi.org/10.37284/eajbe.2.1.185

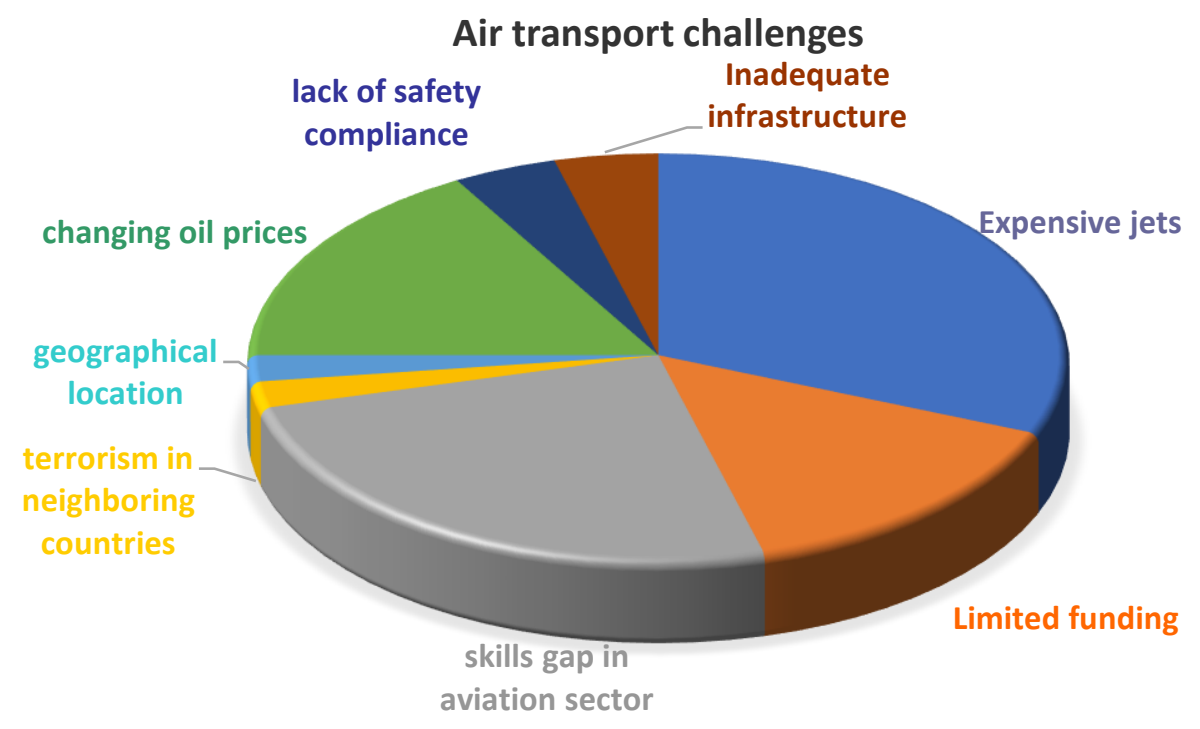

Source: Field survey (2019)

The strategies to improve on air transport operations in Rwanda included; benchmarking best airlines, more funding to air transport industry by government, skills enhancement like training local pilots and engineers, improving airport infrastructure in Rwanda e.g. at Kigali international airport and other domestic airports, oil and energy negotiations with oil-producing countries, space agreements so that RwandAir can fly to other countries with ease. By implementing the following strategies and many others, the air transport will propel to greater heights thus increasing its contribution to the tourism industry in Rwanda.

Strategies to improve air transport operations in Rwanda

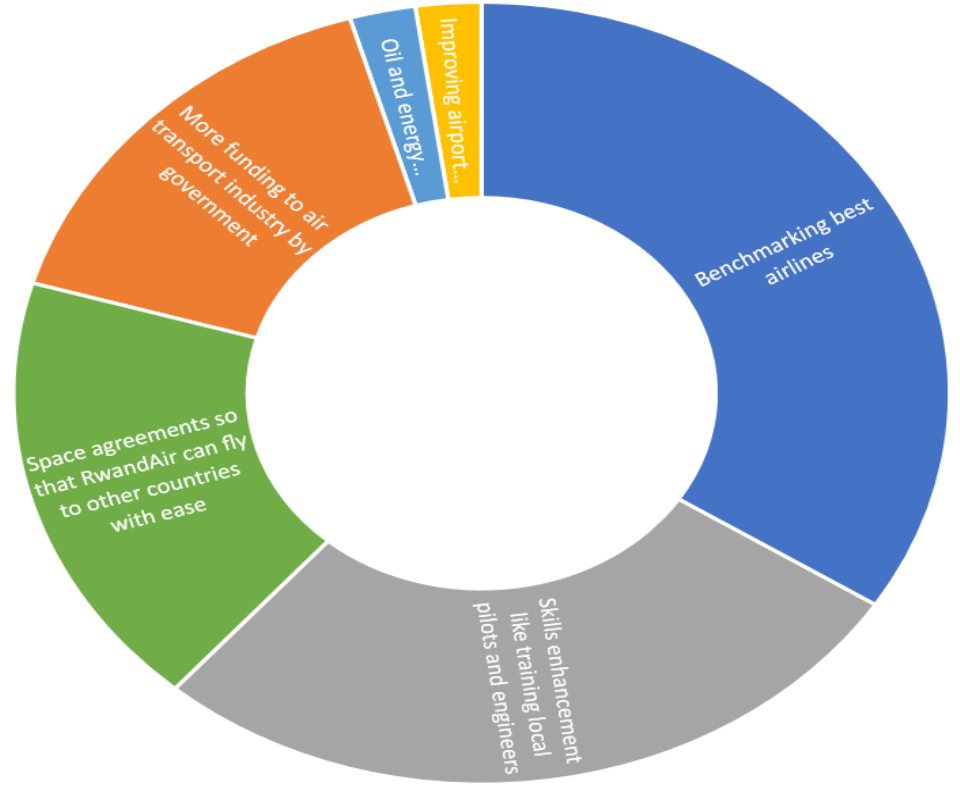

Source: Field survey (2019) 
East African Journal of Business and Economics, Volume 2, Issue 1, 2020

\section{CONCLUSION AND RECOMMENDATIONS}

At the end of this study, the researchers concluded that air transport plays an important role in the development of tourism in Rwanda and that it should be given an upper hand by the government and private players so that it continues to bring more benefits to the tourism and hospitality sector in Rwanda. The findings of this study led to the following recommendations: there should be the opening up of new domestic airports in the country as well as maintaining the existing ones to suit international standards; partnerships should be formed between the government and the private sector for the development of air transport in Rwanda; there should be a reduction in air ticket prices for incoming tourists to the country; government funding disbursed to RwandAir should be increased; more oil and energy negotiations should be done to reduce the variable and fixed costs of the airline; airport infrastructure should be improved, especially at Kigali international airport; skills enhancement like training local pilots and space agreements should be done so that Rwanda air can fly to other countries. The researchers cannot confirm that they fully studied all component of the present study, that's why it's the great opportunity of the researcher to propose the future researchers to study air transport operations and customer satisfaction in Rwanda as well as the role of road transport in tourism development in Rwanda.

\section{REFERENCES}

Africa Infrastructure, (2009). Air Transport Challenges to Growth. Sustainable Development.

Baldasano, J. M., Valera, E., \& Jimenez, P. (2003). Air quality data from large cities. Science of the Total Environment, 307(1-3), 141-165.

Bieger, T., \& Wittmer, A. (2006). Air transport and tourism-Perspectives and challenges for destinations, airlines and governments. Journal of air transport management, 12(1), 40-46.

Carmines, E. G., \& Zeller, R. A. (1979). Reliability and validity assessment (Vol. 17). Sage publications.

Filimonau, V., Dickinson, J., \& Robbins, D. (2014). The carbon impact of short-haul tourism: A case study of UK travel to Southern France using life cycle analysis. Journal of Cleaner Production, 64, 628-638.

Fletcher, J., Fyall, A., Gilbert, D., \& Wanhill, S. (2017). Tourism: Principles and practice. Pearson UK.

Hall, E. T., \& Hall, M. R. (2001). Key concepts: Underlying structures of culture. International HRM: Managing diversity in the workplace, 24-40.

Hall, S., Segal, L., \& Osborne, P. (1997). Stuart Hall: culture and power. Radical Philosophy, $86,24-41$.

Henninger, S. (2009, June). Urban climate and air pollution in Kigali, Rwanda. In The 7th International Conference on Urban Climate (Vol. 29, pp. 1038-1041).

Higham, J. E., Cohen, S. A., \& Cavaliere, C. T. (2014). Climate change, discretionary air travel, and the "Flyers' Dilemma". Journal of Travel Research, 53(4), 462-475. 
IATA-International Air Transport Association. (2009). A global approach to reducing aviation emissions. First stop: carbon-neutral growth from 2020.

ICAO, Annex. (2010). to the Convention on International Civil Aviation. Montreal, Canada, 1 .

Iglesias, C., \& Torgerson, D. (2000). Does length of questionnaire matter? A randomised trial of response rates to a mailed questionnaire. Journal of health services research \& policy, 5(4), 219-221.

Indian, PM. (2011). SUPPLEMENT TO AFRICA RESEARCH BULLETIN. Education and training, 18669, 4.

John Menzies Plc. (2015). Annual Report and Accounts 2015.

Krejcie, R. V., \& Morgan, D. W. (1970). Determining sample size for research activities. Educational and psychological measurement, 30(3), 607-610.

Kuperman, A. J. (2000). Rwanda in retrospect. Foreign Affairs, 94-118.

Leiper, N. (1979). The framework of tourism: Towards a definition of tourism, tourist, and the tourist industry. Annals of tourism research, 6(4), 390-407.

Meleddu, M. (2014). Tourism, Residents'welfare, And Economic Choice: A Literature Review. Journal of Economic Surveys, 28(2), 376-399.

Ndahimana, M., Musonera, E., \& Weber, M. (2013). Assessment of marketing strategies for ecotourism promotion: A case of RDB/tourism and conservation in Rwanda. Journal of Marketing Development and Competitiveness, 7(2), 37-56.
Nsabimana, E. (2010). The extent of community involvement in tourism development and conservation activities in eastern Rwanda (Doctoral dissertation, Cape Peninsula University of Technology).

Nsabimana, E., \& Spencer, J. P. (2013). The potential for eco-tourism in the Gishwati Forest Reserve: An alternative use of the forest for economic upliftment of local communities. African Journal for Physical Health Education, Recreation and Dance, 19(Issue-4_2), 10861099.

Ronald, K., \& Emmy, T. (2019). Broadening of Uganda's Tourism Products and Its Impact on the Tourism Industry: A Case of The Batwa Trail in Uganda.

Rwunguko, J. D. A. (2015). Quantification of transport demand of hybrid lighter than air in Rwanda through stated preference methods (Doctoral dissertation, Stellenbosch: Stellenbosch University).

Samimi, A. J., Sadeghi, S., \& Sadeghi, S. (2017). The relationship between foreign direct investment and tourism development: evidence from developing countries. Institutions and Economies, 59-68.

Shackley, M. (1995). The future of gorilla tourism in Rwanda. Journal of Sustainable Tourism, $3(2), 61-72$.

Simpson, M. C. (2008). Community benefit tourism initiatives-A conceptual oxymoron?. Tourism management, 29(1), 1-18.

SITA, IATA. (1995). World Tracer Management Tracing SITA Baggage Systems Manual.

Sitaula, E. P. (2010). Infrastructure Development in Nepal: Opportunities and Challenges for Engineers: UN: UN Educational, Scientific and Cultural Organization. 
Varhela, A. (2013). Sustainable Tourism Development in post-war Rwanda: Gisenyi.

Varley, R. C. G. (2005). The World Bank and China's Environment 1993-2003, The World Bank. World Bank (1997) Clean water, blue skies: China's environment in the new century, Washington, DC, The World Bank.

World Bank. (2012). World Development Indicators 2012: World Bank Publications.

Yan-jun, X. (2010). On the essence of tourism and its way of cognition: Viewing from the perspective of the discipline itself. Tourism Tribune, 1, 26-31. 